Article

\title{
Single-Pot Synthesis of Biodiesel using Efficient Sulfonated-Derived Tea Waste-Heterogeneous Catalyst
}

\author{
Umer Rashid ${ }^{1, * \mathbb{C}}$, Junaid Ahmad ${ }^{2}$, Mohd Lokman Ibrahim ${ }^{3,4}$, Jan Nisar ${ }^{5}$, \\ Muhammad Asif Hanif ${ }^{6}$ and Thomas Yaw Choong Shean ${ }^{7}$ \\ 1 Institute of Advanced Technology, Universiti Putra Malaysia, UPM Serdang 43400, Selangor, Malaysia \\ Chemical Engineering Department, Khalifa University, Abu Dhabi 127788, United Arab Emirates \\ 3 School of Chemistry and Environment, Faculty of Applied Sciences, Universiti Teknologi MARA, Shah Alam \\ 40450, Selangor, Malaysia \\ 4 Center of Nanomaterials Research, Institute of Sciences, Universiti Teknologi MARA, Shah Alam 40450, \\ Selangor, Malaysia \\ 5 National Centre of Excellence in Physical Chemistry, University of Peshawar, Peshawar 25120, Pakistan \\ 6 Department of Chemistry, University of Agriculture Faisalabad, Faisalabad 38000, Pakistan \\ 7 Department of Chemical and Environmental Engineering, Engineering Faculty, Universiti Putra Malaysia, \\ UPM Serdang 43400, Selangor, Malaysia \\ * Correspondence: umer.rashid@upm.edu.my or umer.rashid@yahoo.com; Tel.: +60-3-97697393
}

Received: 21 May 2019; Accepted: 3 July 2019; Published: 18 July 2019

\begin{abstract}
The main purpose of this manuscript is to report the new usage of tea waste (TW) as a catalyst for efficient conversion of palm fatty acid distillate (PFAD) to biodiesel. In this work, we investigate the potential of tea waste char as a catalyst for biodiesel production before and after sulfonation. The activated sulfonated tea waste char catalyst was characterized using Fourier transform infrared spectroscopy (FTIR), thermogravimetric analysis (TGA), X-ray diffractometry (XRD), elemental composition (CHNS), nitrogen adsorption-desorption using Brunauer-Emmett-Teller (BET) and ammonia-temperature-programmed desorption $\left(\mathrm{NH}_{3}-\mathrm{TPD}\right)$. The activated tea waste char catalyst shows higher acid density of $31 \mu \mathrm{mol} \mathrm{g}-1$ as compared to tea waste char of $16 \mu \mathrm{mol} \mathrm{g}{ }^{-1}$ and higher surface area of $122 \mathrm{~m}^{2} / \mathrm{g}$. The optimum fatty acid conversion conditions were found that $4 \mathrm{wt} \%$ of catalyst loading with 9:1 of methanol:PFAD for $90 \mathrm{~min}$ of reaction time at $65^{\circ} \mathrm{C}$ gives $97 \%$ free fatty acid (FFA) conversion. In conclusion, the sulfonated tea waste (STW) catalyst showed an impressive catalytic activity towards the esterification of PFAD at optimum reaction conditions with significant recyclability in five successive cycles without any reactivation step.
\end{abstract}

Keywords: waste tea-based catalyst; sulfonation; characterization; PFAD-biodiesel

\section{Introduction}

Energy is the key factor of the modern world. Fossil fuel is the leading energy provider among all energy basic sources. Depletion of fossil fuel resources is the hot topic among the energy providers and other stakeholders [1]. Biodiesel has been recognized as a substitute to commercial fuel due to similarity in their characteristics. Biodiesel is a blend of long chain alkyl esters produced through transesterification/esterification reaction of oils or fats with alcohol in the presence of catalyst [2]. The ester production is achieved through transesterification using a homogeneous catalyst i.e., potassium and sodium hydroxide [3]. Conventionally hydrochloric and sulfuric acid were used as homogeneous acid catalysts for the esterification process of feedstock containing high free fatty acids (FFA). The disadvantages of homogeneous acid catalysts are saponification or emulsion formation and 
a complicated and costly separation process is required. Moreover, the purification process is also very complicated and produces a lot of waste $[4,5]$.

Biodiesel are mainly prepared from the edible oils obtained from palm, soya, canola and peanut [6] and it is being predicted that $70 \%$ of the cost of biodiesel production belongs to the feedstock, which is main hurdle in commercialization of this commodity [7]. To minimize the production cost, a variety of non-conventional (non-edible) oils/fats such as rapeseed, tallow, rubber seed oil, kapok seed oil, jatropha oil, palm fatty acid distillate and used cooking oil were investigated by many researchers as substitute to edible oils [8,9]. Palm fatty acid distillate (PFAD) which is one of the waste by-products is produced during the refining process of palm oil and according to Malaysian Palm Oil Board (MPOB), 782048 tonnes of PFAD was produced in 2018, during the processing of palm oil [10]. PFAD consists of more than $85 \mathrm{wt}$ $\%$ of FFA [11]. As the cost of PFAD is much less than refined oil, use of PFAD as feedstock can potentially improve the palm oil waste management and makes more profits for the industry [12].

Currently, several research papers have reported on the novel heterogeneous solid catalyst that have just been developed for various applications, however, only a few research papers have reported the utilization of waste materials as a new valuable catalyst for production of biodiesel $[13,14]$. Heterogeneous catalysts are favored over homogeneous catalysts due to various advantages i.e., they are easily recoverable from the product, less hazardous, compatible in various applications, user friendly, possible in modification, and recyclable which leads to considerable decrease in the production cost [15]. However, the main obstacle faced by researchers and investors is their expensive synthesis which makes the production cost relatively high. In heterogeneous catalysis a support with a high surface area to which the catalyst is affixed is usually very costly and this makes the whole process very expensive [16].

Recently, different types of supports material such as zeolites, mixed oxides, sulphated zirconia, and ion-exchange resins have been used for preparation of heterogeneous catalysts for ester production [17-19]. However, numerous disadvantages associated with the use of these catalysts were reported in terms of cost, intensive reaction conditions, and poor reusability which ultimately increased the production cost of the biodiesel [20,21]. Alternatively, low cost, inexpensive support material produced from biomass gained attraction in the last few years for heterogeneous catalyst preparation [22,23]. In this connection biomass-based carbon or activated carbon gained attraction because of its diverse physiochemical properties, easy availability, and less costly stuff.

Tea is one of most common drinks around the world. Tea (Camellia sinensis) leaves comprises $4-7 \%$ cellulose, $5-6 \%$ lignin, $5-6 \%$ hemicellulose, $14-17 \%$ proteins, $3-7 \%$ lipids and $5-6 \%$ pectin. It is estimated that the production of tea was more than 3.8 million in 2008 [24]. Thousands of tons of tea are used for drinking purposes around the world and this produces a huge pile of solid waste. In Malaysia, tea is used in many different forms and is one of favorite drinks of adults. After preparing tea, the waste is usually disposed of as solid waste. Previously, tea waste was used for different applications such as an adsorbent for industrial wastewater treatment, for preparation of activated carbon (AC) for purification of waste cooking oil esters and for hydrogen production [25-27]. However, there is no such study found in literature on tea waste used for the preparation of acidic catalyst and its application for ester conversion.

PFAD holds a high content of FFA, therefore, the major motive behind this work was to synthesize a novel sulfonated tea waste catalyst for the esterification process of PFAD. Moreover, the detailed characterization and work out of the produced catalyst on the reaction parameters were investigated to achieve better biodiesel production. A reusability study of the produced catalyst has also been studied.

\section{Materials and Methods}

\subsection{Materials}

The discarded black tea leaves were collected from Mama Restaurant located nearby Universiti Putra Malaysia, Malaysia. PFAD was supplied by Sime Darby Jomalina Sdn Bhd, Malaysia. 
Methanol ( $\geq 99.6 \%)$, ethanol (96\%), sulfuric acid (96-98\%), phosphoric acid ( $\geq 98 \%)$ of ACS grade was procured from Merck, Malaysia. The fatty acid methyl esters standards were obtained from Sigma Aldrich, Malaysia.

\subsection{Washing and Cleaning of the Waste Tea Sample}

The discarded black tea samples obtained from the local restaurant were subjected to repeated washing with hot water for removal of color, milk, sugar and other impurities. The samples were then boiled until its color had been removed. The obtained samples were then put in oven at $110^{\circ} \mathrm{C}$ for 24 $\mathrm{h}$, and later the dried sample was grinded and kept in desiccator for further analysis.

\subsection{Chemical Activation of Tea Waste and Char Synthesis}

The tea waste (TW) char was synthesized using the chemical activation method. Briefly, $20 \mathrm{~g}$ of tea waste was soaked in $10 \%$ orthophosphoric acid $\left(\mathrm{H}_{3} \mathrm{PO}_{4}\right)$ solution for $12 \mathrm{~h}$ activation of the tea char waste. After the specified time, it was dried at room temperature and saved for calcination prior to sulfonation. The dried TW powder was carbonized under a stream of $\mathrm{N}_{2}$ by raising the temperature to $700{ }^{\circ} \mathrm{C}$ for $2 \mathrm{~h}$ with a heating rate increase of $5^{\circ} \mathrm{C} / \mathrm{min}$.

\subsection{Synthesis of Sulfonated Tea Waste (TW) Catalyst}

The tea waste and soaked tea waste samples were used to prepare the char samples. Briefly, $10 \mathrm{~g}$ of each tea waste and soaked tea waste were heated to produce incomplete carbonized carbon at $400{ }^{\circ} \mathrm{C}$ for $5 \mathrm{~h}$ in the presence of inert gas at flow of $10 \mathrm{~cm}^{3} \mathrm{~min}^{-1}$. Using hot distilled water, the produced char samples were washed many times until $\mathrm{pH}$ was $\sim 7$, and then dried in oven at $70{ }^{\circ} \mathrm{C}$ for $24 \mathrm{~h}$. From these dried char samples sulfonated acidic catalysts were prepared by mixing $5 \mathrm{~g}$ of each char sample with $98 \%$ concentrated sulfuric acid in a closed cup autoclave and heated at $160{ }^{\circ} \mathrm{C}$ for $6 \mathrm{~h}$. To remove the unreacted sulfuric acid, the obtained catalysts were then washed with hot distilled water $\left(\sim 70^{\circ} \mathrm{C}\right)$. After washing both the catalysts were dried at $70^{\circ} \mathrm{C}$ in an oven overnight for complete removal of moisture. The sulfonated tea waste catalyzed esterification reaction mechanism is presented in Scheme 1.<smiles>[R]C(=O)OC</smiles>

Water Fatty acid methyl esters

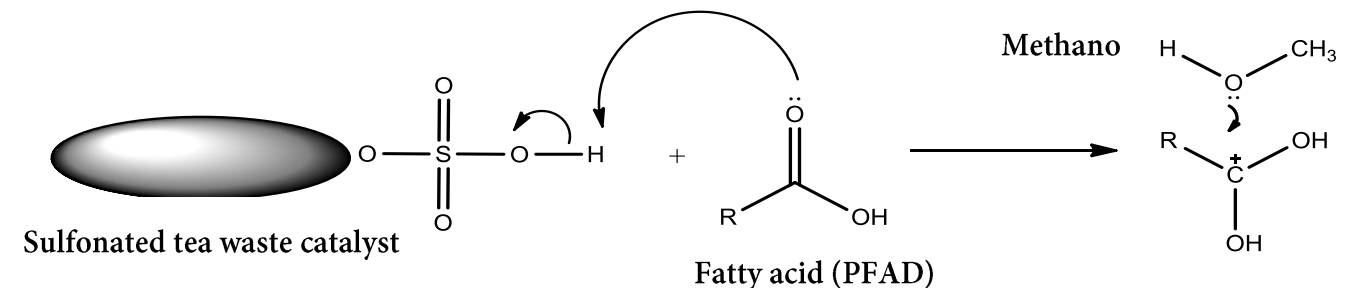

Scheme 1. The sulfonated tea waste catalyzed esterification reaction mechanism. 


\subsection{Physical and Chemical Characterization of Sulfonated Tea Waste (STW) Catalyst}

The prepared sulfonated tea waste (STW) catalysts were analyzed in detail through several instrumentations. Furthermore, the active sites density was assessed by using the temperature programmed desorption of ammonia (ThermoFinnigan, TPDRO 1100 series, Waltham, MA, USA) which was coupled with thermal conductivity detector. Prior to analysis, the sample was flushed with $\mathrm{N}_{2}$ gas for $1 \mathrm{~h}$ and heated up to $150{ }^{\circ} \mathrm{C}$ for removal of any impurities and water moisture in the sample and reactor system. The sample was further pretreated with ammonia gas for $1 \mathrm{~h}$, at ambient temperature to introduce the ammonia molecules on to the catalyst structure. Again, the sample was flushed with $\mathrm{N}_{2}$ gas for 30 min to eliminate any ammonia gas held in the reactor system. The analysis was continued by heating the sample in the temperature range $50{ }^{\circ} \mathrm{C}$ to $950{ }^{\circ} \mathrm{C}$ at $5{ }^{\circ} \mathrm{C} \mathrm{min}^{-1}$ in the presence of helium at a flow rate of $20 \mathrm{~cm}^{3} \mathrm{~min}^{-1}$. The amount of ammonia gas desorbed during the heating process was equivalent to the number of active sites on the catalyst.

The surface characteristics of the STW catalysts were evaluated through $\mathrm{N}_{2}$ adsorption/desorption by using BET micromeritics 3 Flex analyzer (Norcross, GA, USA), while, the crystallinity of the catalyst was determined through X-ray diffraction technique, Shimadzu XRD6000 with scan rate at $2^{\circ} \mathrm{min}^{-1}$ and scan range from $2^{\circ}$ to $80^{\circ}$. The morphological analysis of the catalyst was studied via field emission scanning electron microscope (Lausanne, Switzerland). The introduced functional groups after pretreatment and the activation processes were determined by using the Perkin Elmer, 1725X Fourier transform infrared spectrophotometer (Waltham, MA, USA) The sample was scanned from $500 \mathrm{~cm}^{-1}$ to $4000 \mathrm{~cm}^{-1}$ to get the IR absorption data. Thermal stability of the tea waste char and catalyst were performed using the NETZSCH (STA 449 F3, Netzsch, Selb, Germany) thermogravimetric analyzer. Briefly, a $10 \mathrm{mg}$ of sample was heated from $40{ }^{\circ} \mathrm{C}$ to $900{ }^{\circ} \mathrm{C}$ at $10{ }^{\circ} \mathrm{C} \mathrm{min}-1$ in an inert environment at flow rate of $40 \mathrm{~mL} \mathrm{~min}^{-1}$. Elemental composition (carbon, hydrogen, nitrogen and sulfur content) of tea waste char and synthesized catalyst was determined by Vario MRCO cube analyzer by following the EN151004:2005 standard method.

\subsection{Catalytic Conversion Study}

For esterification of palm fatty acid distillate (PFAD), a $250 \mathrm{~mL}$ three-neck round bottom glass flask outfitted with a condenser, thermocouple and magnetic stirrer was used. The reactor was setup in an oil bath (silicon oil) for homogenized heating on a hot plate. Esterification was performed using $2 \mathrm{wt} \%$ to $5 \mathrm{wt} \%$ of catalyst loading and varying the methanol to PFAD molar ratio from 3:1 to $12: 1$. The reaction was allowed to proceed at $30^{\circ} \mathrm{C}$ to $70{ }^{\circ} \mathrm{C}$ and from $30 \mathrm{~min}$ to $120 \mathrm{~min}$. In each run, $25 \mathrm{~g}$ of PFAD was used and at the end of each reaction, the sample was separated out by using high-speed centrifuge at 7000 RPM for $10 \mathrm{~min}$. After centrifuge, three layers were obtained: the upper layer was ester, the intermediate was water, and the lower layer was solid catalyst. The catalyst separated was collected for a reusability study. The upper layer (ester phase) was further purified using a rotary evaporator to remove the excess methanol and filtered to remove any solid impurities. The purified esters phase was recovered and preserved for further analysis.

The FFA conversion was determined based on Equation (1):

$$
\text { FFA Conversion }(\%)=\frac{A v_{0}-A v_{t}}{A v_{0}} \times 100
$$

where $A_{V o}$ is the initial acid value and $A_{V t}$ is the acid value measured at time $t$.

\subsection{Reusability of The STW Catalyst}

The reusability ability of the STW catalyst was investigated. After the reaction, the separated catalyst was collected and washed with acetone and hexane for removal of the trapped solvent and then the washed catalyst was dried at $70^{\circ} \mathrm{C}$ for $6 \mathrm{~h}$. After every cycle, acid content and ester conversion were determined to check the efficiency of the catalyst. 


\subsection{Statistical Analysis}

Analysis of three different samples was carried out and results were reported as mean $\pm \mathrm{SD}$ and presented in the form of bar graph in figures. Each sample was prepared and measured separately in triplicate for all the reported data.

\section{Results and Discussion}

\subsection{Acid Density Analysis}

Surface area and active acid sites density are the two main factors to determine the level of catalyst activity. Therefore, ammonia temperature programmed desorption $\left(\mathrm{NH}_{3}-\mathrm{TPD}\right)$ was used for measuring the acid strength of tea waste char and sulfonated tea waste catalysts. Table 1 depicts that the sulfonated tea waste (STW) catalyst pre-treated with $\mathrm{H}_{3} \mathrm{PO}_{4}$ exhibited the highest acid density of 31 $\mu \mathrm{mol} \mathrm{g}{ }^{-1}$ as compared to the tea waste (TW) char, which only went through the soaking process with $\mathrm{H}_{3} \mathrm{PO}_{4}$, and showed less total acid density of $16.8 \mu \mathrm{mol} \mathrm{g}^{-1}$. It was also observed that the treatment of the incomplete carbonized tea waste with the phosphoric acid increased surface area of the TW char itself, which gave extra anchor sites for the attachment of the active sulfonic groups on the catalyst structure.

Table 1. Acid density and surface characterization of tea waste char and sulfonated tea waste catalyst.

\begin{tabular}{ccccc}
\hline \multirow{2}{*}{ Sample } & $\mathbf{N H}_{\mathbf{3}}$-TPD Analysis & \multicolumn{3}{c}{ Surface Characteristics } \\
\cline { 2 - 5 } & $\begin{array}{c}\text { Acid Sites Density } \\
\left(\boldsymbol{\mu} \mathbf{m o l} \mathbf{~ g}^{-\mathbf{1}}\right)\end{array}$ & $\begin{array}{c}\text { Average Surface } \\
\text { Area }\left(\mathbf{m}^{\mathbf{2}} \mathbf{~ g}^{-\mathbf{1}}\right)\end{array}$ & $\begin{array}{c}\text { Average Pore } \\
\text { Volume }\left(\mathbf{c m}^{\mathbf{3}} \mathbf{~ g}^{-\mathbf{1}}\right)\end{array}$ & $\begin{array}{c}\text { Average Pore Size } \\
(\mathbf{n m})\end{array}$ \\
\hline $\begin{array}{l}\text { Tea waste char } \\
\begin{array}{l}\text { Sulfonated tea } \\
\text { waste catalyst }\end{array}\end{array}$ & $16.8 \pm 0.48$ & $59 \pm 0.98$ & $0.02 \pm 0.002$ & $4.8 \pm 0.20$ \\
\hline
\end{tabular}

\subsection{Surface Analysis}

In order to get detailed surface characteristics of the catalyst Brunauer-Emmet-Teller (BET) surface area analysis was carried out and the surface area, pore volume and pore size of tea waste char and tea waste char sulfonated catalysts thus determined are presented in Table 1. It was observed that after sulfonation tea waste char surface area was increased from $50 \mathrm{~m}^{2} / \mathrm{g}$ to $122 \mathrm{~m}^{2} / \mathrm{g}$, and this was indicative of the fact that chemical activation had opened the surface pores of the char surface.

\subsection{Functional Group Analysis}

Figure 1 reveals the IR spectra of the tea char and tea char based activated catalyst. The presence of sulfonic groups $\left(-\mathrm{SO}_{3} \mathrm{H}\right)$ can be detected by the IR absorption at $1190 \mathrm{~cm}^{-1}$ for $-\mathrm{SO}_{2}$ asymmetric stretching and at about $1040 \mathrm{~cm}^{-1}$ for the $-\mathrm{SO}_{2}$ symmetric stretching mode $[28,29]$. Almost similar results were also reported by Lokman et al. [30] for a sulfonated carbon catalyst obtained from waste carbohydrates. This shows that the sulfonation process introduced or generated the sulfonic functional groups that covalently bonded on the carbon chain structure of the catalyst. Even though, the hydroxyl group $(-\mathrm{OH})$ was clearly observed by the appearance of the broad absorption peak at around $3500 \mathrm{~cm}^{-1}$ to $3000 \mathrm{~cm}^{-1}$. Another peak was noticed at $1590 \mathrm{~cm}^{-1}$ corresponding to the carbonyl, $\mathrm{C}=\mathrm{O}$ stretching mode for the carboxylic groups, $-\mathrm{COOH}$. 


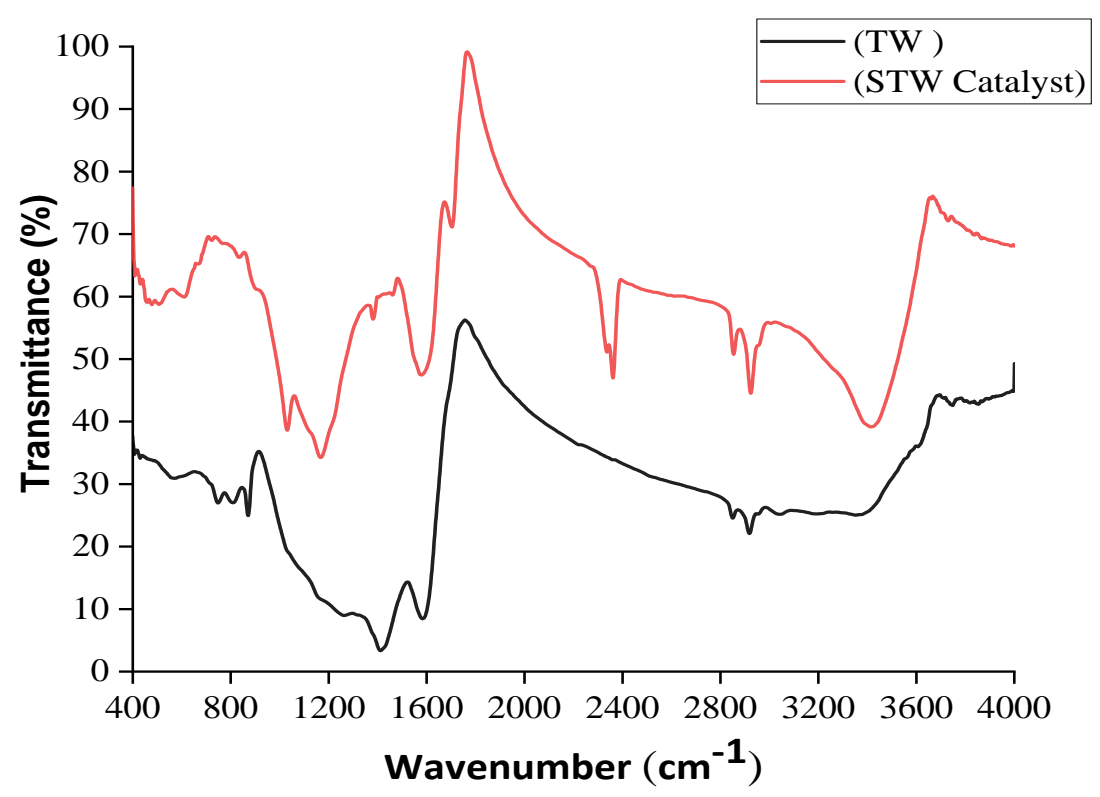

Figure 1. FT-IR spectra of tea waste (TW) char and sulfonated tea waste (STW) catalyst.

\subsection{Morphological Analysis}

The field emission scanning electron microscopy images (FESEM) of tea waste char and sulfonated tea waste catalyst are illustrated in Figure 2. It was found that the FESEM image of sulfonated tea waste char was rough, amorphous and had a heterogeneous structure, whereas the sulfonated tea waste char catalyst which was initially treated with phosphoric acid showed a very clear porous structure on the char surface. Konwar et al. [31] observed that the pretreatment of carbon catalyst with phosphoric acid has led to a porous carbon structure with high surface area associated with highly active sites and these findings agree well with our results.

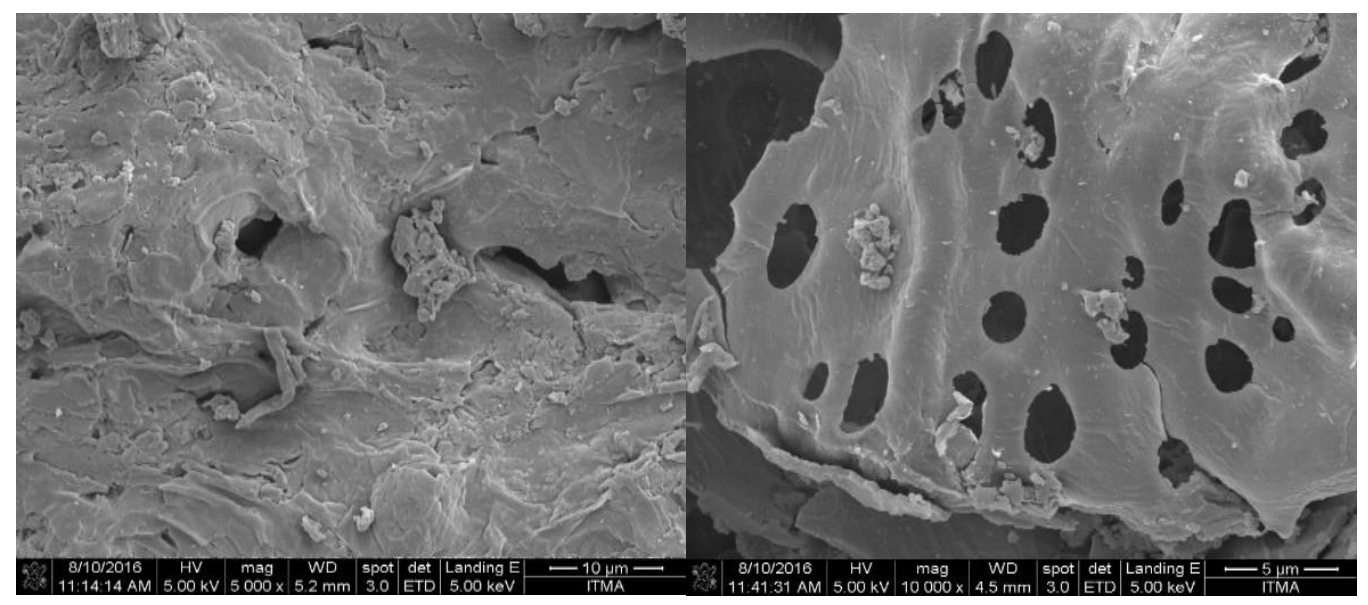

(a)

(b)

Figure 2. Field emission scanning electron microscopy images (FESEM) images of (a) TW-Char (5000x); (b) STW catalyst $(10,000 \times)$.

\subsection{Elemental Composition}

Elemental composition of tea waste char and sulfonated catalyst is presented in Table 2. The results indicate that sulfur contents have increased after sulfonation with successful dispersion on the char surface. 
Table 2. Elemental composition of tea waste (TW) char and synthesized sulfonated tea waste (STW) catalyst.

\begin{tabular}{cccccc}
\hline Samples & $\mathbf{C}$ & $\mathbf{H}$ & $\mathbf{N}$ & $\mathbf{S}$ & $\mathbf{O}^{*}$ \\
\hline Tea waste char & $64.65 \pm 2.15$ & $3.94 \pm 0.10$ & $2.69 \pm 0.11$ & $0.28 \pm 0.12$ & $28.19 \pm 1.25$ \\
\hline Sulfonated tea waste catalyst & $58.55 \pm 1.68$ & $0.77 \pm 0.07$ & $2.71 \pm 0.09$ & $2.67 \pm 0.10$ & $35.3 \pm 0.90$ \\
\hline \multicolumn{6}{c}{ * Calculated by difference. }
\end{tabular}

\subsection{XRD Analysis}

XRD patterns of tea waste char and sulfonated tea waste char catalyst is presented in Figure 3. It was observed that both tea waste char and sulfonated tea waste (STW) catalyst exhibit identical trends of XRD peaks, broad and weak $C(002), C(100)$ and $C(101)$ around $2 \theta$ from $25^{\circ}-28^{\circ}$, and $40^{\circ}-50^{\circ}$, respectively. Whereas, STW catalyst showed the other peaks at around $12^{\circ}, 30^{\circ}, 56^{\circ}-68^{\circ}$ belong to $\mathrm{S}(001), \mathrm{S}(110), \mathrm{S}(111)$ and $\mathrm{S}(004)$ respectively [32]. The presence of sulfur was identified also during the Energy-dispersive X-ray spectroscopy (EDX) analysis (Table 2). The peaks in this region correspond to the amorphous carbon structure which is in accord with the results reported by Yu et al. [33] and Konwar et al. [31].

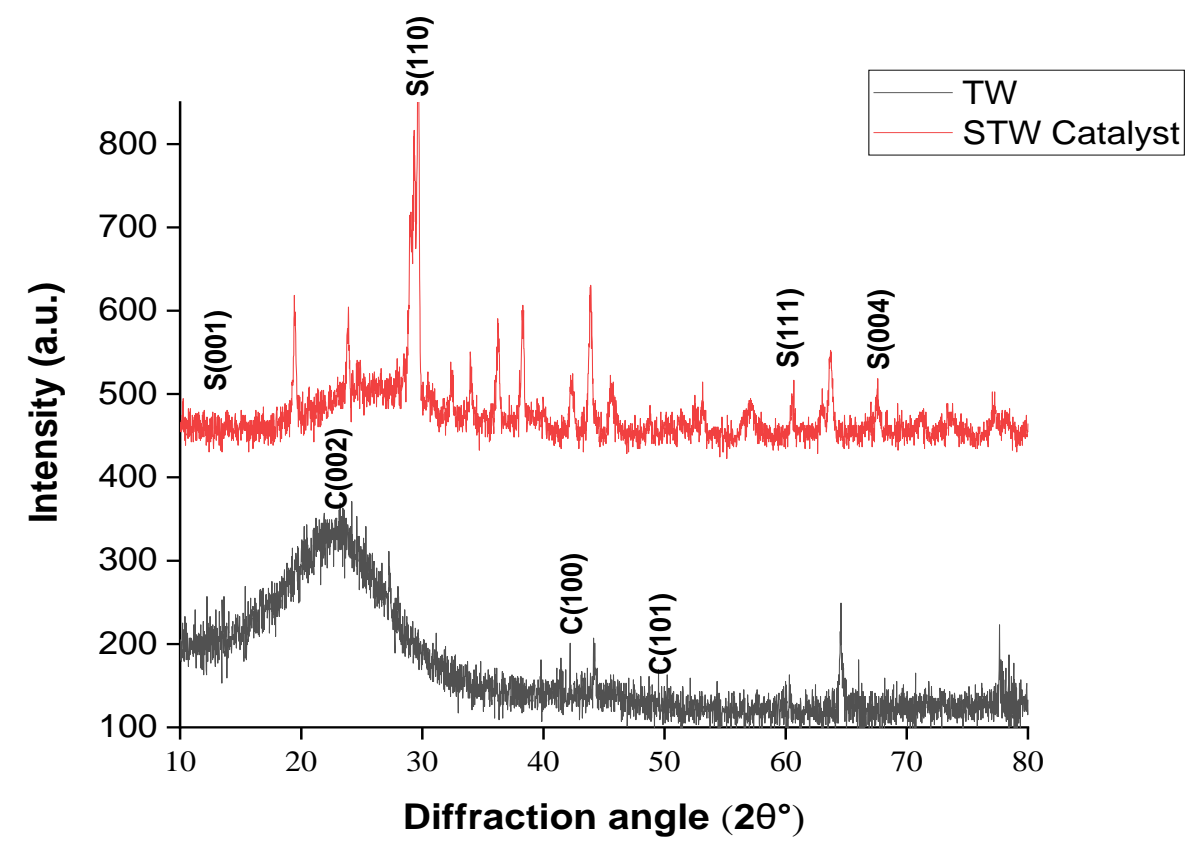

Figure 3. XRD diffractogram of sulfonated-derived tea waste; tea char (black) and sulfonated tea waste acidic catalyst (red).

\subsection{Thermal Stability Analysis}

The thermal stability of tea waste char and tea waste char based acidic catalysts were examined by thermogravimetric analysis. Figure 4 illustrates the mass loss trend of char and catalyst with increasing temperature under inert atmosphere. The tea waste char sample showed a linear kind of trend and by increasing the temperature from $40^{\circ} \mathrm{C}$ to $400{ }^{\circ} \mathrm{C}$ no appreciable mass loss was observed, from $400{ }^{\circ} \mathrm{C}$ to $800^{\circ} \mathrm{C}$ maximum loss in mass was noted and then onward no mass loss was detected. Whereas STW showed a different trend, with maximum mass loss in between $40{ }^{\circ} \mathrm{C}$ to $250{ }^{\circ} \mathrm{C}$ which can be collectively contributed to the evolution of moisture and decomposition/evaporation of $\mathrm{S}$ contents present in $-\mathrm{SO}_{3} \mathrm{H}$. Further mass loss could be credited to the incomplete pyrolysis of tea waste because initially tea waste pyrolysis was performed at $400{ }^{\circ} \mathrm{C}$. Thermogravimetric analysis (TGA) results showed that the tea waste char catalysts were thermally stable for the sulfonation process. 


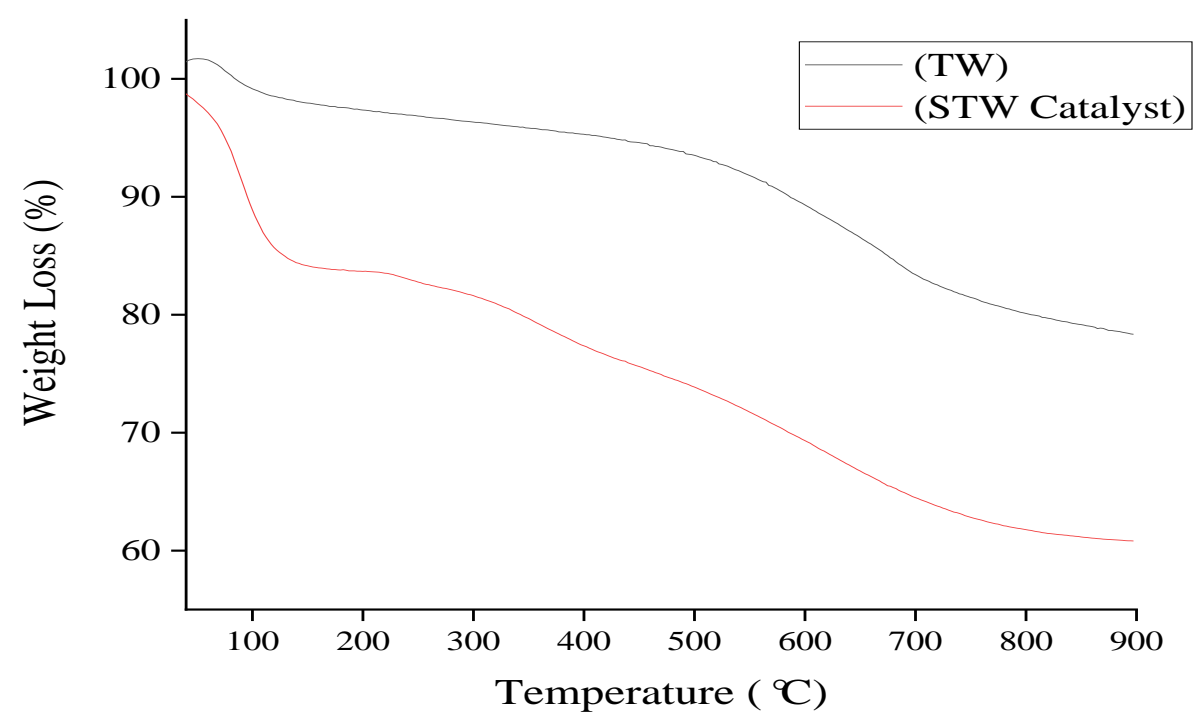

Figure 4. Thermograms of tea waste (TW) char and sulfonated tea waste (STW) acidic catalyst.

\subsection{Factors Affecting Esterification Conversion}

In this study, a sulfonated tea waste (STW) catalyst was used to optimize the four-reaction parameters i.e., methanol:PFAD, catalyst loading, reaction temperature and time for the conversion of PFAD to biodiesel. Efforts were done to utilize the tea waste char as a catalyst, but it gave $\sim 20 \%$ FFA conversion of PFAD.

\subsubsection{Effect of Methanol:PFAD Molar Ratio on FFA Conversion}

Molar ratio is one of the most important factors in the esterification reaction and generally conversion of fatty acid to esters needs three moles of alcohol for one mole of oil. Nevertheless, esterification is a reversible reaction and to move the equilibrium to the forward direction extra amounts of alcohol are required. In this study, several molar ratios (3:1 to 12:1) were tried to achieve maximum conversion of FFA (Figure 5). In this case, 9:1 methanol to PFAD molar ratio was found to be the best ratio for maximum FFA conversion of PFAD of $97 \%$. It was also noted that by enhancing the molar ratio from 9:1 to 12:1, a negative impact was observed and FFA conversion decreased from $97 \%$ to $89 \%$. In an earlier study Mardhiah et al. [4] observed highest FFA conversion at 12:1 and a negative impact on additional enhancement in molar ratio of methanol to oil. This negative impact produced by an increase in molar ratio of methanol to oil may be attributed to the deactivation of the catalyst due to hindering of the active groups on the surface of catalyst which ultimately shifted the equilibrium in the reverse direction. These observations are also in agreement with reported literature $[34,35]$. 


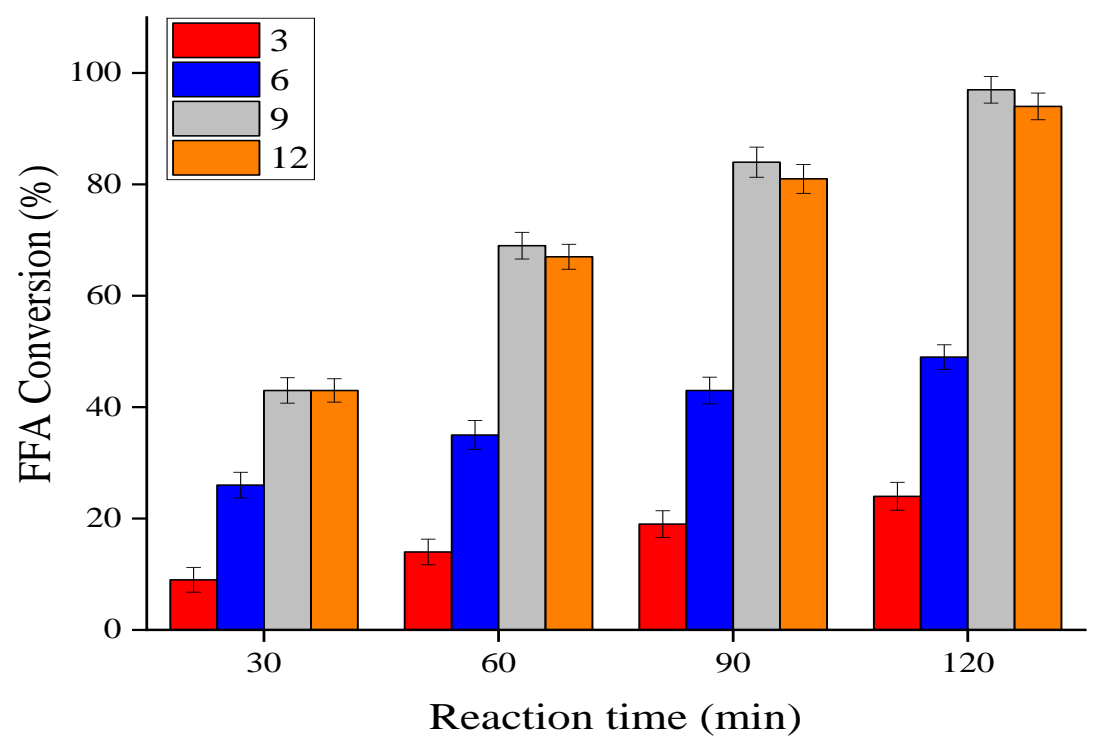

Figure 5. Effect of methanol to palm fatty acid distillate (PFAD) ratio on free fatty acids (FFA) conversion.

\subsubsection{Effect of Catalyst Loading}

The catalyst helps to increase the reaction rate by decreasing the activation energy of the process, and therefore, increasing the amount of catalyst surely speeds up the conversion of reactants into products [36]. In this study, different catalyst concentration ranges from $2 \mathrm{wt} \%$ to $5 \mathrm{wt} \%$ was used for FFA conversion. It was noted that by raising the amount of catalyst the FFA conversion was also increased as indicated in Figure 6 . The peak FFA conversion was achieved at $4 \mathrm{wt} \%$ of catalyst, however, further increase in the catalyst amount showed negative effect and a reduction in FFA conversion was noted. It may probably be credited to the difference of mass transfer in between FFA content and catalyst active sites and therefore, excess amount of catalyst disturbed the reaction equilibrium [37]. In earlier reported studies a similar trend was also observed, and the authors noted that, after a certain limit further increase in catalyst showed negative results [38,39].

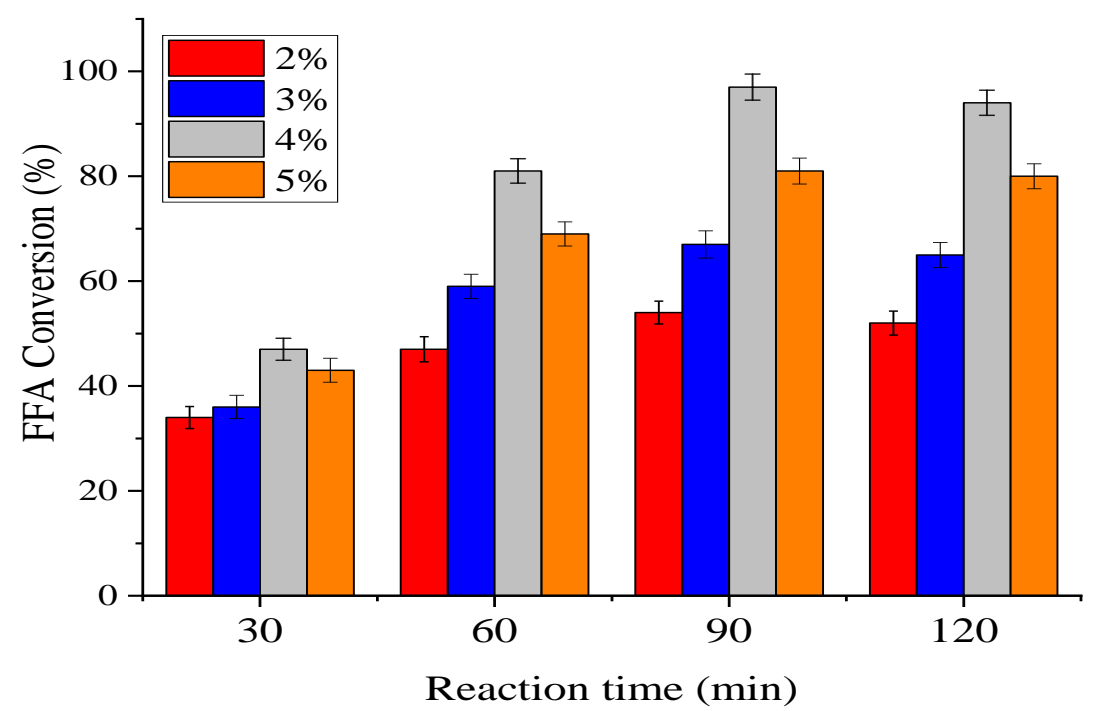

Figure 6. Effect of catalyst loading on FFA conversion. 


\subsubsection{Effect of Reaction Temperature}

Temperature directly effects any reaction rate and it is also a cost dependent variable of any process. In order to confirm this, different temperatures range from $45^{\circ} \mathrm{C}$ to $70{ }^{\circ} \mathrm{C}$ were used for the esterification of PFAD, keeping other parameters constant i.e., catalyst loading $4 \mathrm{wt} \%$, methanol:PFAD molar ratio 9:1 and reaction time $90 \mathrm{~min}$ at $350 \mathrm{RPM}$ (Figure 7). It was observed that by rising temperature from $45{ }^{\circ} \mathrm{C}$ to $65{ }^{\circ} \mathrm{C}$ the FFA conversion improved from $35 \%$ to $97 \%$. Temperatures above $65{ }^{\circ} \mathrm{C}$ to $75{ }^{\circ} \mathrm{C}$ showed negative impact and the end result was a decrease in FFA conversion from $97 \%$ to $94 \%$. There are many reasons behind this decrease in FFA conversion after a certain limit. However, the most important one is the evaporation and bubbling out of methanol at a temperature higher than the boiling point of methanol which results in a continuous decrease in methanol content in the reaction mixture and thus sufficient methanol is not available for FFA conversion at temperatures more than the boiling point of methanol $[40,41]$.

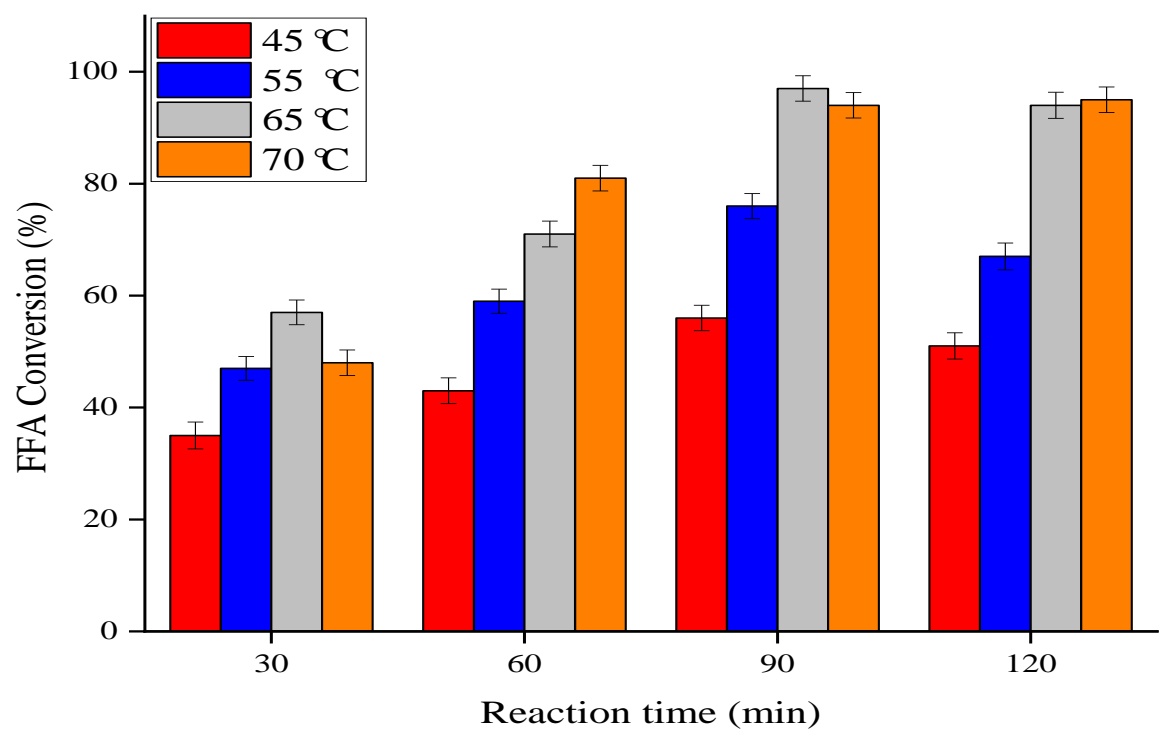

Figure 7. Effect of reaction temperature on FFA conversion.

\subsubsection{Effect of Reaction Time on FFA Conversion}

The influence of reaction time was investigated from $30 \mathrm{~min}$ to $120 \mathrm{~min}$ keeping other parameters constant such as catalyst loading of $4 \mathrm{wt} \%$, methanol to PFAD molar ratio 9:1 and reaction temperature $65{ }^{\circ} \mathrm{C}$ at $350 \mathrm{RPM}$ (Figure 8). It was observed that with an increase in reaction time FFA conversion was observed to increase. Maximum FFA conversion of $97 \%$ was achieved at $90 \mathrm{~min}$ of reaction time; however, further increase in reaction time reduced the FFA conversion. These observations are in conformity with earlier reported results $[42,43]$. There are several possible reasons of a decrease in the FFA conversion after $90 \mathrm{~min}$, such as increase in water concentration within the reaction media which has a profound effect on the catalyst activity and ultimately FFA conversion is decreased. Moreover, long reaction time also weakens the bonding of the active group from the carbon surface and thus an increase in leaching of sulfonic groups adversely affects the catalyst activity [41]. 


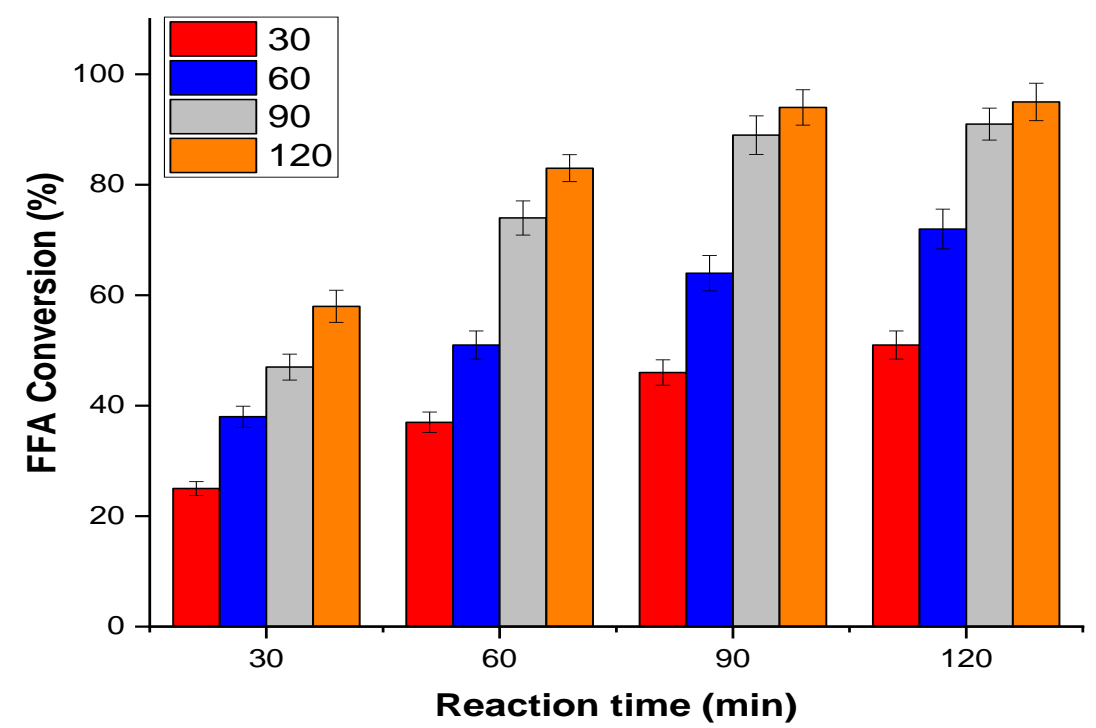

Figure 8. Effect of reaction time on FFA conversion.

\subsection{Regeneration and Reusability of STW Catalyst}

The regeneration and reusability of STW was evaluated and the obtained results are illustrated in Figure 9. The esterification reaction was performed at catalyst loading of $4 \mathrm{wt} \%$, methanol to PFAD ratio as 9:1, reaction temperature $65^{\circ} \mathrm{C}$ and reaction time $90 \mathrm{~min}$. At the end of each run, the catalyst was recovered by filtration and washed with acetone followed by ethanol and distilled to purify it from all the trapped/adsorbed unwanted polar and non-polar compounds. It was observed that the STW catalyst could be used up to five consecutive runs without losing much activity. STW showed a FFA conversion of the PFAD from $96 \%$ to $68 \%$ after being reused for six times. This indicates that the STW catalyst works well until five cycles. The regeneration and reusability of STW catalyst showed that it has the potential to be used on a commercial scale. 


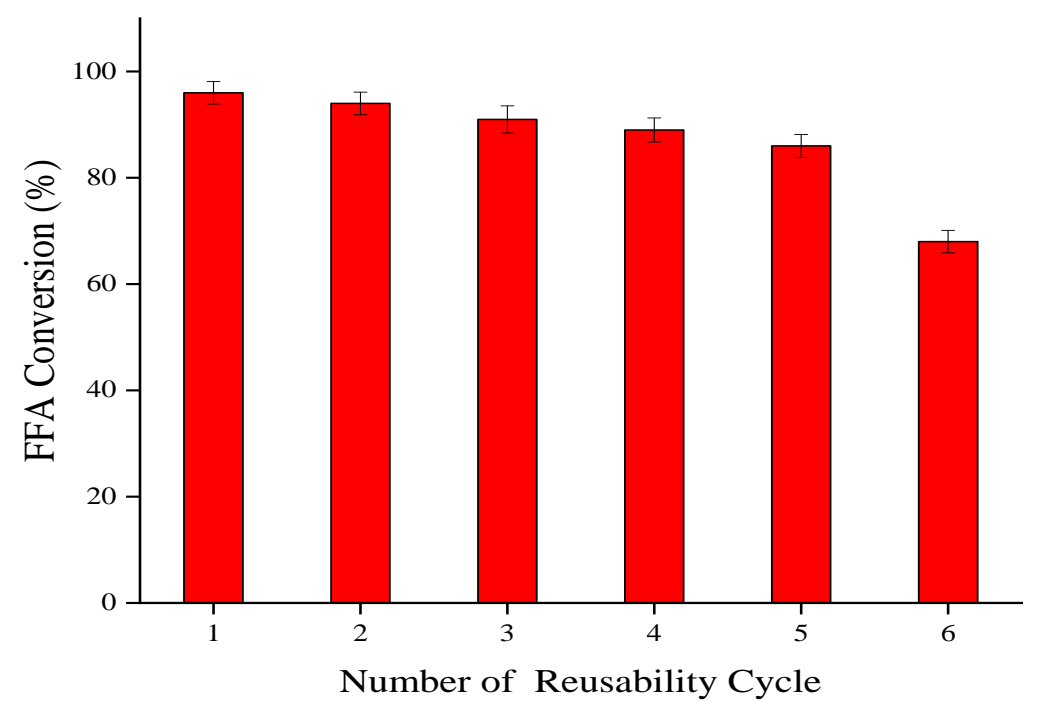

Figure 9. Regeneration/reusability of the STW catalyst.

3.10. Comparison of Catalytic Activity of Different Residues Valorized as Sulfonated Char Catalysts for Esterification

A summary of the catalytic activity of different residues valorized as catalyst support in the synthesis of sulfonated char catalysts to produce esters, or biodiesel is presented in Table 3. Sulfonated sugarcane bagasse, sulfonated multiwalled carbon nanotubes and sulfonated magnetic solid acid catalysts need higher methanol to PFAD molar ratio and reaction temperature, whereas, sulfonated sugarcane bagasse requires more catalyst loading as compared to the sulfonated tea waste catalyst. However, sulfonated tea waste (produced in this study) showed better reaction time as compared to previously synthesized catalysts. The catalyst produced in this study showed better reusability as compared to sulfonated sugarcane bagasse, cacao shell-derived solid acid catalyst, sulfonating carbonized corn straw and sulfonated magnetic solid acid catalysts (Table 3). Hence, the catalyst produced from sulfonated tea waste in the present study is expected to be an effective solid acid catalyst for the esterification of PFAD and could also be used for other high FFA feedstocks. 
Table 3. Catalytic activity of different residues valorized as sulfonated char catalysts for esterification.

\begin{tabular}{|c|c|c|c|c|c|c|c|}
\hline \multirow{2}{*}{ Catalysts } & \multirow{2}{*}{ Feedstock } & \multicolumn{4}{|c|}{ Reaction Parameters } & \multirow{2}{*}{ Reusability } & \multirow{2}{*}{ References } \\
\hline & & Methanol/Oil or PFAD Ratio & Catalyst Loading (\%) & Temperature $\left({ }^{\circ} \mathrm{C}\right)$ & Time (h) & & \\
\hline Sulfonated sugarcane bagasse & PFAD & $20: 1$ & 11.5 & 170 & 0.5 & 1 run & [44] \\
\hline Sulfonated multiwalled carbon nanotubes & PFAD & $20: 1$ & 3 & 170 & 2 & 5 runs & [45] \\
\hline Sulfonated magnetic solid acid catalysts & Oleic acid & 12:1 & 9 & 90 & 5 & 4 runs & [46] \\
\hline Cacao shell-derived solid acid catalyst & Oleic acid & $7: 1$ & 5 & 42 & 4 & 4 runs & [47] \\
\hline Sulfonating carbonized corn straw & Oleic acid & $7: 1$ & 7 & 60 & 4 & - & [48] \\
\hline Sulfonated tea waste & PFAD & 9:1 & 4 & 65 & 1.5 & 5 runs & This study \\
\hline
\end{tabular}




\section{Conclusions}

In short, a highly active sulfonated tea waste (STW) catalyst was prepared from the waste material by wet impregnation method using sulfuric acid as an active agent for PFAD conversion through esterification. The catalytic activity was studied to investigate the catalyst efficiency by studying the process optimization conditions. The optimization conditions revealed that the catalyst worked very well at a low temperature of $65^{\circ} \mathrm{C}$, with catalyst loading of $4 \mathrm{wt} \%$, by using 9:1 PFAD to methanol ratio for $90 \mathrm{~min}$ of reaction time and gave $97 \%$ FFA conversion. The STW catalyst characterization results revealed that it showed very high acid density, external thermal stability and a porous nature. Regeneration and reusability of STW catalyst shows very good results up to five cycles with good FFA conversion ability. This indicates that catalyst is feasible on a commercial scale because of its diverse properties i.e., it is inexpensive, works on lower temperature and can be used multiple times. The authors believe that the STW based solid acid catalyst is an appealing catalyst for PFAD conversion into esters.

Author Contributions: The conceptualization of this journal article is from U.R. The experimental work and methodology were designed by J.A.; the writing - original draft was prepared by J.A. and U.R. helped with the editing and supervision and reviewing of the manuscript. T.Y.C.S. provided the scientific guidance for the successful completion of the project and helped to review the final draft of the manuscript. M.L.I. helped to investigate the catalysts and M.A.H. helped to review the final draft of the paper and also assisted in the biodiesel analysis. J.N. helped to rearrange the content of the paper and also improving its language.

Funding: The authors want to extend their profound gratitude for the financial support from the Universiti Putra Malaysia under project GP-IPB/2016/9490400.

Conflicts of Interest: There has been no conflict of interest declared by the authors.

\section{References}

1. Mahmudul, H.M.; Hagos, F.Y.; Mamat, R.; Adam, A.A.; Ishak, W.F.W.; Alenezi, R. Production, characterization and performance of biodiesel as an alternative fuel in diesel engines-A review. Renew. Sust. Energ. Rev. 2017, 72, 497-509. [CrossRef]

2. Taufiq-Yap, Y.H.; Teo, S.H.; Rashid, U.; Islam, A.; Hussien, M.Z.; Lee, K.T. Transesterification of Jatropha curcas crude oil to biodiesel on calcium lanthanum mixed oxide catalyst: Effect of stoichiometric composition. Energ. Convers. Manage. 2014, 88, 1290-1296. [CrossRef]

3. Munoz, R.A.A.; Fernandes, D.M.; Santos, D.Q.; Barbosa, T.G.G.; Sousa, R.M.F. Biodiesel: Production, characterization, metallic corrosion and analytical methods for contaminants. In Biodiesel-Feedstocks, Production and Applications; Fang, Z., Ed.; InTech: London, UK, 2012; pp. 129-176.

4. Mardhiah, H.H.; Ong, H.C.; Masjuki, H.H.; Lim, S.; Pang, Y.L. Investigation of carbon-based solid acid catalyst from Jatropha curcas biomass in biodiesel production. Energ. Convers. Manage. 2017, 144, 10-17. [CrossRef]

5. López, D.E.; Goodwin, J.G.; Bruce, D.A.; Lotero, E. Transesterification of triacetin with methanol on solid acid and base catalysts. Appl. Catal. A-Gen. 2005, 295, 97-105. [CrossRef]

6. Kligerman, D.C.; Bouwer, E.J. Prospects for biodiesel production from algae-based wastewater treatment in Brazil: A review. Renew. Sust. Energ. Rev. 2015, 52, 1834-1846. [CrossRef]

7. Tao, L.; Aden, A. The economics of current and future biofuels. In Biofuels: Global Impact on Renewable Energy, Production Agriculture and Technological Advancement; Tomes, D., Lakshmanan, P., Songstad, D., Eds.; Springer: New York, NY, USA, 2011; pp. 37-70.

8. Rashid, U.; Ahmad, J.; Yunus, R.; Ibrahim, M.; Masood, H.; Syam, A.M. Momordica charantia seed oil methyl esters: A kinetic study and fuel properties. Int. J. Green Energy 2014, 11, 727-740. [CrossRef]

9. Demirbas, A. Progress and recent trends in biodiesel fuels. Energ. Convers. Manage. 2009, 50, 14-34. [CrossRef]

10. Malaysian Palm Oil Board (MPOB). Refinery: Monthly Production of Selected Processed Palm Oil for the Month of December 2018. Available online: http://bepi.mpob.gov.my/index.php/en/statistics/production/186production-2018/846-production-of-processed-palm-oil-2018.html (accessed on 26 April 2019). 
11. Metre, A.V.; Nath, K. Super phosphoric acid catalyzed esterification of palm fatty acid distillate for biodiesel production: Physicochemical parameters and kinetics. Pol. J. Chem. Technol. 2015, 17, 88-96. [CrossRef]

12. Malaysian Palm Oil Board (MPOB). Overview of Malaysian Palm Oil Industry 2018. Available online: http://bepi.mpob.gov.my/images/overview/Overview_of_Industry_2018.pdf (accessed on 25 April 2019).

13. Dejean, A.; Ouédraogo, I.W.K.; Mouras, S.; Valette, J.; Blin, J. Shea nut shell based catalysts for the production of ethanolic biodiesel. Energy Sustain. Dev. 2017, 40, 103-111. [CrossRef]

14. Devi, B.L.A.P.; Gangadhar, K.N.; Prasad, P.S.S.; Jagannadh, B.; Prasad, R.B.N. A glycerol-based carbon catalyst for the preparation of biodiesel. ChemSusChem 2009, 2, 617-620. [CrossRef]

15. Pukale, D.-D.; Maddikeri, G.-L.; Gogate, P.-R.; Pandit, A.-B.; Pratap, A.-P. Ultrasound assisted transesterification of waste cooking oil using heterogeneous solid catalyst. Ultrason. Sonochem. 2015, 22, 278-286. [CrossRef] [PubMed]

16. Essamlali, Y.; Amadine, O.; Fihri, A.; Zahouily, M. Sodium modified fluorapatite as a sustainable solid bi-functional catalyst for biodiesel production from rapeseed oil. Renew. Energ. 2019, 133, 1295-1307. [CrossRef]

17. Alhassan, F.H.; Rashid, U.; Taufiq-Yap, Y.H. Synthesis of waste cooking oil-based biodiesel via effectual recyclable bi-functional $\mathrm{Fe}_{2} \mathrm{O}_{3} \mathrm{MnOSO}_{4}{ }^{2-} / \mathrm{ZrO}_{2}$ nanoparticle solid catalyst. Fuel 2015, 142, 38-45. [CrossRef]

18. Soltani, S.; Rashid, U.; Nehdi, I.A.; Al-Resayes, S.I. Esterification of palm fatty acid distillate using a sulfonated mesoporous $\mathrm{CuO}-\mathrm{ZnO}$ mixed metal oxide catalyst. Chem. Eng. Technol. 2017, 40, 1931-1939. [CrossRef]

19. Dal Pozzo, D.M.; Azevedo Dos Santos, J.A.; Júnior, E.S.; Santos, R.F.; Feiden, A.; Melegari De Souza, S.N.; Burgardt, I. Free fatty acids esterification catalyzed by acid Faujasite type zeolite. RSC Adv. 2019, 9, 4900-4907. [CrossRef]

20. Konwar, L.J.; Boro, J.; Deka, D. Review on latest developments in biodiesel production using carbon-based catalysts. Renew. Sust. Energ. Rev. 2014, 29, 546-564. [CrossRef]

21. Mansir, N.; Taufiq-Yap, Y.H.; Rashid, U.; Lokman, I.M. Investigation of heterogeneous solid acid catalyst performance on low grade feedstocks for biodiesel production: A review. Energ. Convers. Manage. 2017, 141, 171-182. [CrossRef]

22. Sharma, A.; Pareek, V.; Zhang, D. Biomass pyrolysis-A review of modelling, process parameters and catalytic studies. Renew. Sust. Energ. Rev. 2015, 50, 1081-1096. [CrossRef]

23. Konwar, L.J. Biochar supported Cao as heterogeneous catalyst for biodiesel production. Int. J. Innov. Res. Dev. 2012, 1, 186-195.

24. Mahmood, T.; Hussain, S.T. Nanobiotechnology for the production of biofuels from spent tea. Afr. J. Biotechnol. 2010, 9, 858-868.

25. Ayas, N.; Esen, T. Hydrogen production from tea waste. Int. J. Hydrogen Energ. 2016, 41, 8067-8072. [CrossRef]

26. Fadhil, A.B.; Dheyab, M.M. Purification of biodiesel using activated carbons produced from spent tea waste. J. Assn. Arab Univ. Basic Appl. Sci. 2012, 11, 45-49. [CrossRef]

27. Malakahmad, A.; Tan, S.; Yavari, S. Valorization of wasted black tea as a low-cost adsorbent for nickel and zinc removal from aqueous solution. J. Chem. 2016, 5680983. [CrossRef]

28. Ormsby, R.; Kastner, J.R.; Miller, J. Hemicellulose hydrolysis using solid acid catalysts generated from biochar. Catal. Today 2012, 190, 89-97. [CrossRef]

29. Mar, W.W.; Somsook, E. Sulfonic-functionalized carbon catalyst for esterification of high free fatty acid. Procedia Eng. 2012, 32, 212-218. [CrossRef]

30. Lokman, I.M.; Rashid, U.; Taufiq-Yap, Y.H.; Yunus, R. Methyl ester production from palm fatty acid distillate using sulfonated glucose-derived acid catalyst. Renew. Energ. 2015, 81, 347-354. [CrossRef]

31. Konwar, L.J.; Das, R.; Thakur, A.J.; Salminen, E.; Mäki-Arvela, P.; Kumar, N. Biodiesel production from acid oils using sulfonated carbon catalyst derived from oil-cake waste. J. Mol. Catal. A-Chem. 2014, 388-389, 167-176. [CrossRef]

32. Doroodmand, M.M.; Sobhani, S.; Ashoori, A. Sulfonated multiwalled carbon nanotubes (MWCNTs) as a new, efficient, and recyclable heterogeneous nanocatalyst for the synthesis of amines. Can. J. Chem. 2012, 90, 701-707. [CrossRef]

33. Yu, J.T.; Dehkhoda, A.M.; Ellis, N. Development of Biochar-based Catalyst for Transesterification of Canola Oil. Energ. Fuel. 2011, 25, 337-344. [CrossRef] 
34. Shu, Q.; Gao, J.; Nawaz, Z.; Liao, Y.; Wang, D.; Wang, J. Synthesis of biodiesel from waste vegetable oil with large amounts of free fatty acids using a carbon-based solid acid catalyst. Appl. Energ. 2010, 87, 2589-2596. [CrossRef]

35. Abu-Jrai, A.M.; Jamil, F.; Al-Muhtaseb, A.H.; Baawain, M.; Al-Haj, L.; Al-Hinai, M. Valorization of waste Date pits biomass for biodiesel production in presence of green carbon catalyst. Energ. Convers. Manage. 2017, 135, 236-243. [CrossRef]

36. Rao, B.V.S.K.; Chandra Mouli, K.; Rambabu, N.; Dalai, A.K.; Prasad, R.B.N. Carbon-based solid acid catalyst from de-oiled canola meal for biodiesel production. Catal. Commun. 2011, 14, 20-26. [CrossRef]

37. Akinfalabi, S.-I.; Rashid, U.; Yunus, R.; Taufiq-Yap, Y.H. Synthesis of biodiesel from palm fatty acid distillate using sulfonated palm seed cake catalyst. Renew. Energ. 2017, 111, 611-919. [CrossRef]

38. Amani, H.; Ahmad, Z.; Hameed, B.H. Highly active alumina-supported Cs-Zr mixed oxide catalysts for low-temperature transesterification of waste cooking oil. Appl. Catal. A-Gen. 2014, 487, 16-25. [CrossRef]

39. Ezebor, F.; Khairuddean, M.; Abdullah, A.Z.; Boey, P.L. Oil palm trunk and sugarcane bagasse derived solid acid catalysts for rapid esterification of fatty acids and moisture-assisted transesterification of oils under pseudo-infinite methanol. Bioresour. Technol. 2014, 157, 254-262. [CrossRef]

40. Yu, H.; Niu, S.; Lu, C.; Li, J.; Yang, Y. Preparation and esterification performance of sulfonated coal-based heterogeneous acid catalyst for methyl oleate production. Energ. Convers. Manage. 2016, 126, 488-496. [CrossRef]

41. Tao, M.-L.; Guan, H.-Y.; Wang, X.-H.; Liu, Y.-C.; Louh, R.-F. Fabrication of sulfonated carbon catalyst from biomass waste and its use for glycerol esterification. Fuel Process. Technol. 2015, 138, 355-360. [CrossRef]

42. Thushari, I.; Babel, S. Sustainable utilization of waste palm oil and sulfonated carbon catalyst derived from coconut meal residue for biodiesel production. Bioresour. Technol. 2018, 248, 199-203. [CrossRef]

43. Chen, G.; Fang, B. Preparation of solid acid catalyst from glucose-starch mixture for biodiesel production. Bioresour. Technol. 2011, 102, 2635-2640. [CrossRef]

44. Chin, L.H.; Abdullah, A.Z.; Hameed, B.H. Sugar cane bagasse as solid catalyst for synthesis of methyl esters from palm fatty acid distillate. Chem. Eng. J. 2012, 183, 104-107. [CrossRef]

45. Shuit, S.H.; Tan, S.H. Biodiesel production via esterification of palm fatty acid distillate using sulphonated multi-walled carbon nanotubes as a solid acid catalyst: Process study, catalyst reusability and kinetic study. Bioenerg. Res. 2015, 8, 605-617. [CrossRef]

46. Wang, Y.-T.; Yang, X.-X.; Xu, J.; Wang, H.-L.; Wang, Z.-B.; Zhang, L.; Wang, S.-L.; Liang, J.-L. Biodiesel production from esterification of oleic acid by a sulfonated magnetic solid acid catalyst. Renew. Energ. 2019, 139, 688-695. [CrossRef]

47. Bureros, G.M.A.; Tanjay, A.A.; Cuizon, D.E.S.; Go, A.W.; Cabatingan, L.K.; Agapay, R.C.; Ju, Y.-H. Cacao shell-derived solid acid catalyst for esterification of oleic acid with methanol. Renew. Energ. 2019, 138, 489-501. [CrossRef]

48. Liu, T.; Li, Z.; Li, W.; Shi, C.; Wang, Y. Preparation and characterization of biomass carbon-based solid acid catalyst for the esterification of oleic acid with methanol. Bioresour. Technol. 2013, 133, 618-621. [CrossRef] [PubMed]

(C) 2019 by the authors. Licensee MDPI, Basel, Switzerland. This article is an open access article distributed under the terms and conditions of the Creative Commons Attribution (CC BY) license (http://creativecommons.org/licenses/by/4.0/). 